Maria Aparecida Torres Mourão Amâncio a Márcia Herculiani Cardillo ${ }^{a}$

Marisol Watanabe

a Centro de Referência Regional em Saúde do Trabalhador. Campinas, SP, Brasil.

Contato:

Maria Aparecida Torres Mourão Amâncio

E-mail:

tidatorres@gmail.com

As autoras declaram que não há conflitos de interesses e que o trabalho não recebeu qualquer tipo de financiamento.

As autoras informam que o trabalho não foi fundamentado em tese ou dissertação, nem apresentado em reunião científica.

\section{Atenção à saúde do trabalhador de postos de revenda de combustíveis: relato sobre a implantação de programa de vigilância e de estratégia de acolhimento de trabalhadores em Campinas/SP}

\author{
Health care for gas station workers: a report about the \\ implementation of a health surveillance program and a worker \\ embracement strategy in Campinas, São Paulo, Brazil
}

\title{
Resumo
}

Introdução: o Centro de Referência Regional em Saúde do Trabalhador (Cerest) e a Vigilância em Saúde do município de Campinas/SP, junto com a Comissão Estadual do Benzeno (São Paulo) e a Comissão Regional do Benzeno (Campinas), desenvolveram o Projeto Frentista, no período de 2005 a 2012, visando à implantação de um programa de atenção à saúde dos trabalhadores de postos de revenda de combustíveis (PRC) no município de Campinas. Objetivo: relatar o desenvolvimento e os resultados do projeto e avaliar a prática do acolhimento de trabalhadores como estratégia de atuação. Métodos: o projeto ocorreu em etapas, iniciando com a realização de um diagnóstico situacional e a elaboração/ implantação de um protocolo de atenção à saúde dos trabalhadores de PRC. Um projeto-piloto abrangendo dez PRC e 136 trabalhadores foi realizado entre fevereiro de 2009 e outubro de 2010. Resultados: foram identificadas condições de trabalho que determinavam riscos de exposição ao benzeno e problemas de saúde possivelmente relacionados. Conclusão: a alta adesão dos trabalhadores ao projeto referendou as estratégias adotadas. Vislumbra-se a possibilidade de utilizar essa experiência para subsidiar a constituição de protocolos específicos por ramo de atividade de trabalho como estratégia de vigilância em saúde.

Palavras-chave: benzeno; combustíveis; vigilância; acolhimento; saúde do trabalhador.

\begin{abstract}
Introduction: the Regional Reference Center in Occupational Health (Cerest) and the Health Surveillance Department of the city of Campinas, along with the State Benzene Commission (São Paulo) and the Regional Benzene Commission (Campinas), developed the Gas Station Attendant Project, from 2005 to 2012, aiming at establishing a health care program for gas station workers in the city of Campinas. Objective: to report the project development and its results and to evaluate the practice of workers embracement as a strategy of action. Methods: the project was developed in stages, starting with a situational diagnosis and the preparation and establishment of a health care protocol for gas station attendants. A pilot project covering 10 gas stations and 136 attendants was carried out between February 2009 and October 2010. Results: the project identified working conditions resulting in benzene exposure risks and health problems which might be related to it. Conclusion: the workers' high commitment to the project endorsed the adopted strategies. This experience may be used to subsidize the establishment of specific protocols by branch of work activity as a health surveillance strategy.
\end{abstract}

Keywords: benzene; fuels; surveillance; user embracement; occupational health. 


\section{Introdução}

A Comissão Regional do Benzeno de Campinas foi criada em 23 de setembro de 2005 e nesse período de implantação identificou a situação de risco enfrentada pelos frentistas, sinalizada pela ocorrência de casos de leucopenia entre trabalhadores de postos de revenda de combustíveis (PRC) ${ }^{1}$.

O Centro de Referência Regional em Saúde do Trabalhador de Campinas (Cerest/Campinas) recebeu seu primeiro caso de trabalhador frentista com diagnóstico de leucopenia em 2006, procedente de um posto de combustível que praticava adulteração de gasolina. Por meio desse trabalhador, chegaram ao Cerest mais três frentistas do mesmo posto, que também tinham problemas de saúde (leucopenia, hepatite tóxica e agravamento de crises de convulsão). Entendendo-se a gravidade da situação, foi iniciado um projeto para atender as questões relacionadas à saúde dos trabalhadores dos PRC, levando em consideração também experiências anteriores do Cerest e da Vigilância Sanitária (Visa) de Campinas com protocolos de ações voltadas para populações expostas a riscos químicos em áreas contaminadas, como, por exemplo: Protocolo Mansões Santo Antônio/Proquima ${ }^{2}$ e Protocolo da Shell/Cyanamid/Basf ${ }^{3}$. Essas ações e experiências foram alvo de pesquisa sobre a importância da constituição de rede para o desenvolvimento da vigilância em saúde do trabalhador e ambiental em PRC ${ }^{4}$.

Nesse contexto, em 2007, o projeto-piloto para implantação da vigilância à saúde dos trabalhadores nos PRC, intitulado Projeto frentista de Campinas, foi iniciado de fato com a Oficina de vigilância em saúde dos trabalhadores expostos ao benzeno, pelo Centro de Vigilância Sanitária da Divisão Saúde do Trabalhador da Secretaria de Saúde do Estado de São Paulo, com apoio da Comissão Estadual do Benzeno de São Paulo. Seu objetivo foi capacitar os técnicos das equipes de Vigilância Sanitária e Epidemiológica das regionais da Secretaria do Estado da Saúde de São Paulo, dos Centros de Referência em Saúde do Trabalhador (Cerests) e do Instituto Adolfo Lutz. Essa capacitação foi preconizada pela Portaria do Ministério da Saúde $\mathrm{n}^{\circ}$ 776, de 28 de abril de 2004, para incentivar a criação de comissões regionais de acompanhamento do Acordo Nacional do Benzeno.

O Ministério do Trabalho e Emprego de Curitiba e o Centro Estadual de Referência em Saúde do Trabalhador da Secretaria de Saúde do Estado da Bahia (Cesat/BA) já atuavam em programas específicos com os PRC em suas áreas de abrangência. Assim, na oficina, tivemos a oportunidade de discutir suas experiências e avaliar possíveis contribuições para nossa realidade. Em Curitiba, a equipe de trabalho adotou estratégias de convocação dos proprietários de PRC para apresentar o Termo de Ajuste e Conduta de Proteção e Saúde dos Trabalhadores. Enquanto no Cesat/BA, o foco de intervenção ocorreu pelo programa de Vigilância da Saúde dos Trabalhadores, por meio de inspeções nos PRC 5 .

Em Campinas, inicialmente, o projeto previa atender os trabalhadores expostos que manipulavam combustíveis adulterados. No entanto, a partir das discussões sobre o projeto na Comissão Regional do Benzeno de Campinas e da Vigilância Ambiental do município, o foco foi direcionado aos PRC de áreas contaminadas, tendo em vista a magnitude destes na listagem das áreas contaminadas da Companhia Ambiental do Estado de São Paulo (Cetesb) (em maio de 2005, 73\% do total das áreas contaminadas no estado de São Paulo eram áreas de PRC).

A partir da conjunção dessas experiências de vigilância em saúde, pode-se dizer que o projeto, desde o início, teve como preocupação considerar toda a complexidade do problema, entendendo-o como uma ação multidisciplinar, intersetorial e interinstitucional ${ }^{4,5-7}$. Assim, contribuíram para o projeto os seguintes fatores: 1) já havia no Cerest uma experiência em assistência e vigilância em casos de exposição e intoxicações em áreas contaminadas nos municípios de Campinas ${ }^{2}$ e Paulínia ${ }^{3}$ (Mansões Santo Antônio e Shell/Basf); 2) a Vigilância Ambiental do município de Campinas estava cadastrando as áreas contaminadas, que em sua maioria eram de PRC, para os Programas de Vigilância da Qualidade da Água para Consumo Humano - Vigiágua $^{8}$ e Vigilância em Saúde de Populações Expostas a Solo Contaminado - Vigisolo ${ }^{9}$ ); 3) a experiência do Cesat/ BA ofereceu uma referência em vigilância em PRC.

Conforme o projeto foi sendo elaborado, surgiu a necessidade da formação de um Grupo de Trabalho (GT), multiprofissional e interinstitucional, para debater e acompanhar a implantação do projeto. A Comissão Estadual do Benzeno de São Paulo esteve presente em todas as reuniões do GT, num processo contínuo de acompanhamento e formação técnica. O Cesat/BA também contribuiu em vários momentos desse processo, principalmente, com a capacitação da equipe técnica do Cerest e da Visa.

Foram delineadas duas grandes frentes de trabalho que ocorreram simultaneamente. Uma voltada para a avaliação ambiental e de riscos à saúde dos trabalhadores nos PRC, que foi realizada pela Vigilância em Saúde trabalhador do município. Outra, voltada à avaliação de saúde de cada um dos trabalhadores daqueles PRC.

As avaliações individuais dos trabalhadores foram realizadas pela equipe do Cerest, que utilizou as ferramentas do acolhimento, da história clínica e ocupacional, exame físico e exames complementares indicados para monitoramento biológico e investigação 
diagnóstica de doenças que eventualmente fossem constatadas durante a avaliação clínica, além da avaliação audiológica.

Com relação ao acolhimento, são muitas as definições sobre essa prática, contudo o Cerest/Campinas já o desenvolve desde 1998, aprimorando-o a cada necessidade surgida. Segundo o Núcleo Técnico da Política Nacional de Humanização do Ministério da Saúde, o termo "acolhimento" é:

Acolher é dar acolhida, admitir, aceitar, dar ouvidos, dar crédito a, agasalhar, receber, atender, admitir [...] $\mathrm{O}$ acolhimento como ato ou efeito de acolher expressa, em suas várias definições, uma ação de aproximação, um "estar com" e um "estar perto de", ou seja, uma atitude de inclusão ${ }^{10}$.

O acolhimento consiste na humanização das relações entre trabalhadores e serviço de saúde com seus usuários ${ }^{11}$. $\mathrm{O}$ acolhimento se diferencia da triagem, pois não é um mero atendimento em que o acolhedor decide se acolhe ou não:

O encontro entre esses sujeitos se dá num espaço [...] no qual se produz uma relação de escuta e responsabilização, a partir do que se constituem vínculos e compromissos que norteiam os projetos de intervenção. Esse espaço permite que o trabalhador use de sua principal tecnologia, o saber, tratando o usuário como sujeito portador e criador de direitos ${ }^{12}$.

A estratégia do acolhimento representa o primeiro vínculo a ser criado entre o profissional de saúde e o trabalhador/paciente, uma vez que ele pode ser o responsável pela aderência do trabalhador ao tratamento na unidade e aos propósitos da responsabilização por sua saúde.

O objetivo deste trabalho foi relatar o desenvolvimento do Projeto frentista do Cerest/Campinas, projeto este que teve seus primórdios na articulação da Comissão Regional do Benzeno em 2005, passando pela realização de Projeto-piloto para atendimento de trabalhadores e fiscalização de dez PRC, até chegar à consolidação de protocolo para atendimento dos trabalhadores e fiscalização de PRC pela atenção básica e vigilância em saúde de Campinas. Neste relato, demos ênfase à importância do acolhimento na identificação das condições de trabalho e procedimentos de risco para exposição ao benzeno aos quais estavam expostos os trabalhadores de PRC, bem como à boa adesão dos trabalhadores ao acompanhamento de saúde proposto.

\section{Métodos}

Após as articulações interinstitucionais e definição dos postos de combustíveis como uma das prioridades elencadas pela Comissão Regional do Benzeno, os procedimentos metodológicos adotados foram os seguintes:

1) Levantamento e mapeamento dos PRC do município, identificando aqueles localizados em áreas contaminadas, a partir dos dados do Programa Vigisolo e do Cetesb;

2) Escolha de dez PRC, definidos para o projeto-piloto, de modo aleatório, sendo dois postos de combustíveis para cada equipe de vigilância (cinco distritos de saúde);

3) Adequação da Ficha de Inspeção do Cesat/BA para a realidade de Campinas;

4) Elaboração da relação de documentos e procedimentos padronizados a serem solicitados pela Visa aos postos vistoriados e suas notificações;

5) Definição dos exames laboratoriais básicos para o atendimento dessa demanda;

6) Elaboração da ficha de acolhimento;

7) Estabelecimento de fluxo de atendimento no Cerest;

8) Elaboração de banco de dados para tratamento das informações coletadas em acolhimento.

Depois das etapas de levantamento, mapeamento e escolha dos dez PRC, as inspeções foram iniciadas. Para fins de assistência à saúde, um fluxo de informação entre os técnicos da Visa e o Cerest foi estabelecido a partir da obtenção da lista dos nomes dos trabalhadores de cada PRC. Com essa relação, a equipe do Cerest organizou uma agenda integrada para que cada trabalhador passasse pelos três atendimentos no mesmo dia/período:

1) acolhimento - realizado pela equipe multiprofissional com uma assistente social, uma enfermeira, uma fisioterapeuta, uma fonoaudióloga e duas terapeutas ocupacionais. Cada profissional agendava cerca de quatro trabalhadores por período, que eram atendidos individualmente e recebiam toda orientação sobre o Projeto frentista e os riscos da exposição ocupacional ao benzeno. A ficha de acolhimento era preenchida durante o atendimento, de forma dinâmica, servindo como roteiro de orientações básicas sobre os principais procedimentos de trabalho que potencializam riscos para essa categoria profissional, numa duração média de uma hora;

2) consulta de fonoaudiologia com realização de exame audiológico; 
3) consulta médica para avaliação clínica com solicitação de exames laboratoriais (hemograma completo, urina 1, função hepática: TGO-TGP e Gama GT); e renal (ureia e creatinina) realizados em Laboratório SUS. O trabalhador se dirigia à unidade básica de sua área de referência, para colher os exames. Os resultados desses exames eram encaminhados para o Cerest, e o paciente era convocado novamente para retorno em consulta médica.

Os dados contidos na ficha de acolhimento, após atendimento, foram digitados em banco de dados com auxílio do programa estatístico Epi Info 6, em seguida, a ficha foi arquivada no prontuário do trabalhador. As informações colhidas nas avaliações audiológicas e consultas médicas foram avaliadas separadamente.

\section{Resultados}

De 2005 a 2008, ocorreram as articulações interinstitucionais na Comissão Regional e Estadual do Benzeno, Centro de Vigilância Sanitária, Cesat da Bahia, além das articulações dentro da própria Secretaria de Saúde de Campinas entre Vigilância Ambiental, Vigilâncias Distritais e Cerest, até a formação do GT. A partir disso foram definidos os locais e trabalhadores a serem avaliados, bem como os instrumentos de avaliação, com início de sua aplicação a partir de 2009.

\section{Caracterização da população atendida}

No período de fevereiro de 2009 a outubro de 2010, o Cerest/Campinas atendeu 136 trabalhadores dos dez PRC selecionados como piloto.
A Tabela 1 mostra que 44\% (60) dos trabalhadores eram jovens com até 30 anos de idade, sendo que mais de três quartos deles (46) tinham até quatro anos de trabalho na função. Por outro lado, 53\% (72) do total dos trabalhadores acima de 21 anos de idade viveram de cinco a mais de 21 anos de suas vidas produtivas expostos ao benzeno.

A Tabela 2 mostra que, dos 102 frentistas (frentista, frentista caixa e frentista/trocador de óleo), quase metade $(n=49 ; 48 \%)$ estava há menos de cinco anos, cerca de um quarto estava entre cinco e dez anos $(n=26 ; 25,5 \%)$, e o restante estava há mais de dez anos ( $n=27 ; 26,5 \%)$ na função, caracterizando, assim, um tempo de exposição prolongado, potencializando os riscos de adoecimento.

A informação sobre as exposições anteriores a produtos químicos na anamnese ocupacional tem importância como uma referência na avaliação dos riscos de exposição e do agravamento da doença. Em relação à história ocupacional, mais da metade (59\%) dos trabalhadores relataram exposição anterior à gasolina em outras atividades profissionais e $48,5 \%$ informaram contato anterior com outros produtos químicos de risco ocupacional, como: agrotóxicos; produtos de limpeza; solventes; Diisocianato de Tolueno; amônia; benzina; tintas (automotivas e para mobiliário); colas (cola de sapateiro); verniz; querosene; Metasil ${ }^{\mathrm{TM}}$; Solupan; óleo (lubrificante); corantes; ceras; gases tóxicos; pó de gesso e Aguarrás. Vale ressaltar que a maior frequência encontra-se na exposição a agrotóxicos e solventes.

Houve grande adesão à proposta do projeto, pois 90\% dos 136 trabalhadores fizeram acompanhamento de saúde proposto, apresentando, inclusive, preocupações com relação a seus familiares.

Tabela 1 Tempo de trabalho e faixa etária de trabalhadores expostos a benzeno em dez postos de revenda de combustíveis. Campinas, 2009-2010

\begin{tabular}{|c|c|c|c|c|c|c|c|c|c|}
\hline \multirow{2}{*}{ Faixa etária } & \multicolumn{9}{|c|}{ Tempo na atividade (anos) } \\
\hline & $<1$ & $1 a 2$ & $3 a 4$ & $5 a 6$ & $7 a 8$ & $9 a 10$ & 11 a 20 & $>21$ & Total \\
\hline$<21$ & 4 & 3 & - & - & - & - & - & - & 7 \\
\hline 21 a 30 & 11 & 16 & 12 & 7 & 7 & - & - & - & 53 \\
\hline 31 a 40 & 1 & 2 & 9 & 6 & 6 & 6 & 12 & 2 & 44 \\
\hline 41 a 50 & - & 2 & 4 & 2 & - & - & 9 & 6 & 23 \\
\hline 51 a 60 & - & - & - & - & - & - & 3 & 3 & 6 \\
\hline$>60$ & - & - & - & 1 & - & - & 1 & 1 & 3 \\
\hline Total & 16 & 23 & 25 & 16 & 13 & 6 & 25 & 12 & 136 \\
\hline
\end{tabular}

Fonte: Prontuários do Cerest/Campinas. 
Tabela 2 Função e tempo na profissão de trabalhadores expostos ao benzeno em dez postos de revenda de combustíveis. Campinas, 2009-2010

\begin{tabular}{lcccccc}
\hline & \multicolumn{7}{c}{ Tempo na profissão (anos) } & & \\
& \multicolumn{1}{c}{ Função } & 1 a & 5 a 10 & 11 a 20 & $>20$ & Total \\
\hline Frentista & 11 & 31 & 15 & 15 & 5 & 77 \\
Frentista caixa & - & 6 & 6 & 1 & 1 & 14 \\
Frentista/Trocador de óleo & - & 1 & 5 & 1 & 4 & 11 \\
Lavador de carro & 2 & 1 & 6 & - & - & 9 \\
Auxiliar administrativo & - & 3 & 1 & 3 & - & 7 \\
Atendente de vendas & - & 4 & - & 1 & - & 5 \\
Balconista (conveniência) & 2 & 3 & - & - & - & 5 \\
Vigia noturno & - & - & 1 & 1 & - & 2 \\
Secretária & - & - & 1 & 1 & - & 2 \\
Supervisor de pista & - & - & - & 1 & - & 1 \\
Gerente & - & - & - & - & 1 & 1 \\
Motorista de carreta & - & - & - & 1 & - & 1 \\
Chefe de pista & - & - & - & - & 1 & 1 \\
Total & 15 & 49 & 35 & 25 & 12 & 136 \\
\hline
\end{tabular}

Fonte: Prontuários do Cerest/Campinas.

\section{Caracterização das situações e riscos nas atividades laborativas}

Observou-se que $13 \%$ dos trabalhadores faziam rodízios de turno. Desses, $49 \%$ realizavam horas extras, na maioria das vezes nos períodos de folga (aos domingos).

Quanto aos procedimentos de trabalho que potencializam riscos, como mostrado na Figura 1, considerando os 120 trabalhadores que entravam em contato direto com os combustíveis, observou-se que os mais frequentes foram: aproximação do rosto no abastecimento "até a boca do tanque" (63,8\%); uso do "paninho" para absorver derrames de combustíveis no enchimento dos tanques $(53,3 \%)$ e na coleta de amostra do caminhão-tanque (43,3\%). Entretanto, ressalta-se que os procedimentos denominados "banho de combustível" (quando o trabalhador é atingido por respingos acidentais de combustível) e de "aspirar o combustível com a mangueira" (para retirar combustível do tanque) tiveram alta frequência de informação não coletada, pelo fato dessas questões, inicialmente, não estarem presentes na ficha de acolhimento (só foram introduzidas após o relato dos trabalhadores). Esses procedimentos potencializam a exposição ao produto químico. São hábitos e incidentes resultantes de intercorrências do trabalho, assim como de inadequações do encaixe do bico da bomba no tanque de combustível de alguns carros ou retorno do combustível para fora do tanque no momento do abastecimento, dentre outros.

\section{Caracterização dos problemas de saúde dos trabalhadores}

Os sintomas referidos pelos trabalhadores na etapa do acolhimento estão apresentados na Figura 2. A cefaleia se destaca como um dos mais frequentes $(n=59,44,1 \%)$. Diante dos sintomas e de outros problemas de saúde relatados ou identificados, do total dos trabalhadores, quarenta e seis $(33,8 \%)$ referiram fazer uso de algum tipo de medicamento. As classes terapêuticas dos medicamentos de uso mais frequente foram: broncodilatadores; antiasmáticos; anti-hipertensivos; contraceptivos; hipoglicemiantes; imunossupressores; anti-histamínicos; relaxantes musculares; antimicrobianos; anti-inflamatórios; analgésicos; antipiréticos; antiepilético; anticonvulsionantes; antidepressivos; diuréticos; homeopáticos; antirretrovirais/inibidores de protease; descongestionante nasal; antiulceroso; multivitamínicos.

Em relação aos afastamentos do trabalho por motivo de doença e acidentes de trabalho, dos 136 trabalhadores atendidos, vinte e nove $(21,3 \%)$ relataram afastamento do trabalho, pelos seguintes motivos: fadiga por trabalho noturno (1); transtorno mental (1); hepatite e hérnia esofágica (1); crise de hipertensão (1); crise de asma (1); stress e erisipela (1); problemas de coluna (2); tratamento de HIV (1); paralisia facial (1); pielonefrite (1); litíase de vesícula biliar (1); estado gripal (3); dengue (1), ardência nos olhos (1); conjuntivite (2); traumas na residência (2); acidente de trabalho típico (4) e de trajeto (4). 


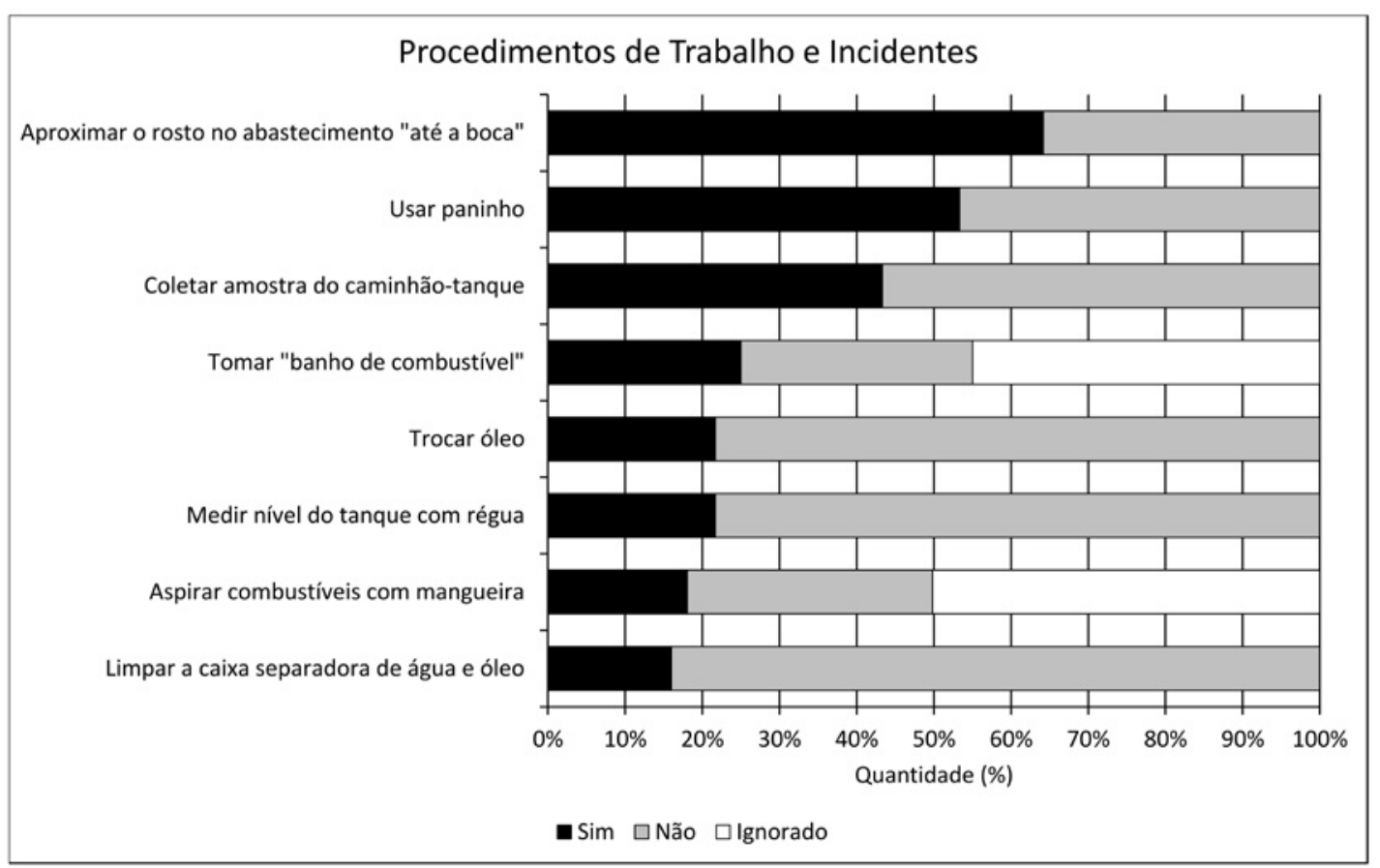

Figura 1 Procedimentos de trabalho e incidentes que potencializam a exposição a produtos químicos, relatados por trabalhadores frentistas de dez postos de revenda de combustíveis. Campinas, 2009-2010

Fonte: Relatórios de Vigilância à Saúde do Trabalhador, Cerest/Campinas.

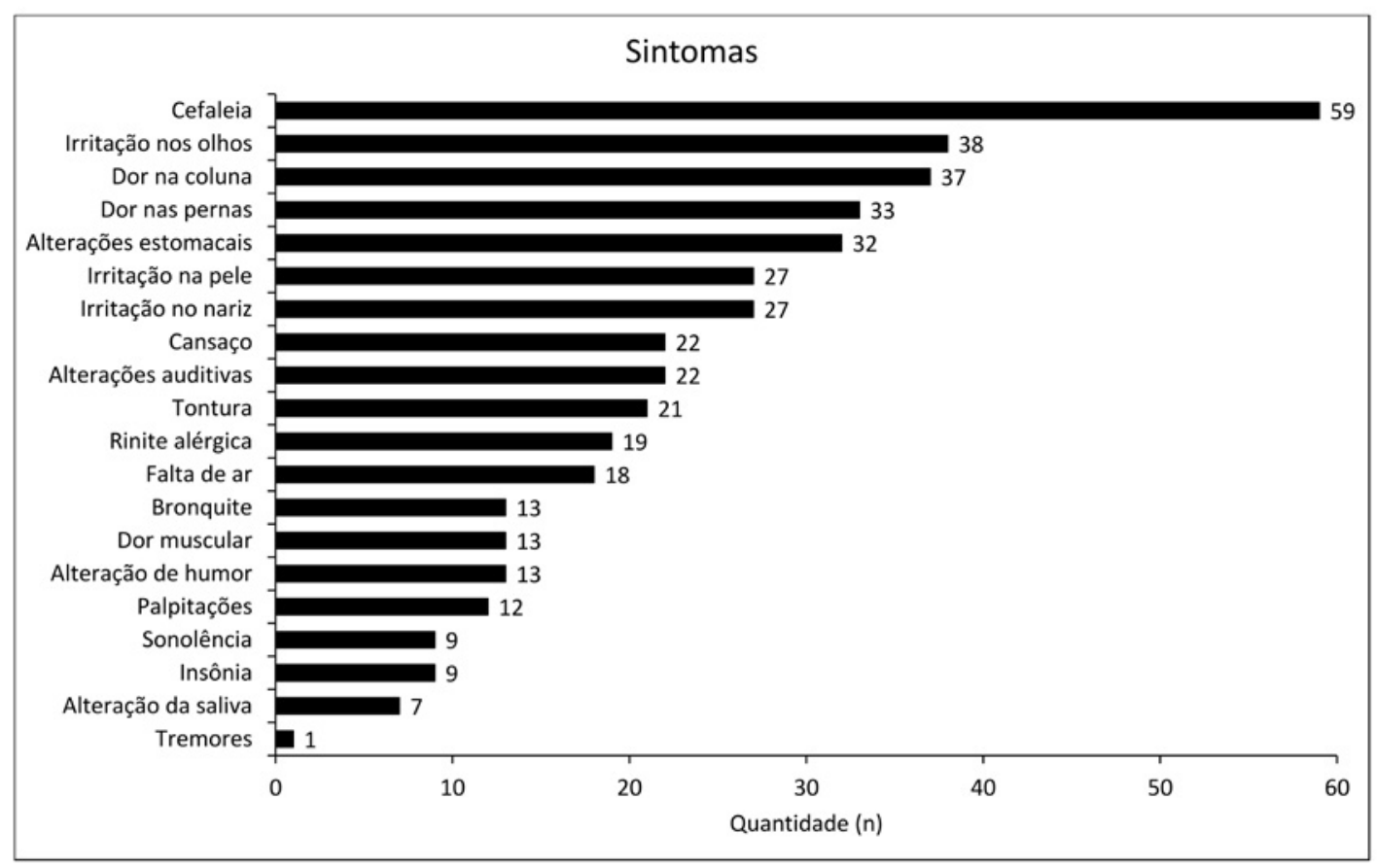

Figura 2 Sintomas referidos por 136 trabalhadores clinicamente avaliados de dez postos de revenda de combustíveis. Campinas, 2009-2010

Fonte: Prontuários do Cerest/Campinas. 
Em relação às intercorrências/situações de risco e acidentes relatados, seguem alguns exemplos:

1) "tomei um banho com o diesel [...] respingou no olho e ficou inflamado" (sem afastamento, continuou trabalhando);

2) "queimadura nos olhos com combustível - o bico do tanque virou no rosto” (dois dias de afastamento);

3) “queimadura na troca de óleo" - sem uso de Equipamento de Proteção Individual - EPI (sem afastamento);

4) "ingestão de combustível, apresentou asfixia" (não foi ao médico);

5) “ingestão de combustível ao usar a mangueira é comum [...] mas o patrão não abriu a CAT porque não sabe [...] porque acredita ser normal";

6) "ao abrir a tampa do radiador queimou o braço” (não abriu a Comunicação de Acidente de Trabalho, CAT);

7) “ao abrir o capô do carro, a mangueira do radiador estourou [...] fez movimento brusco e rápido [...] teve torção e deslocamento da coluna” (foi no hospital e abriu CAT);

8) “às vezes, agressão verbal e física de alguns clientes alcoolizados”;

9) “atropelamento de funcionários - teve um carro que passou sobre o meu pé” (sem abertura da CAT);

10) "assaltos frequentes à mão armada, em geral sem vítimas" (houve um caso que um frentista foi refém por dez minutos);

11) "veículo pegou fogo durante o abastecimento";

12) "um carro pegando fogo entrou no posto de combustível [...] e os frentistas tentando tirá-lo do local [...]”;

13) "carro saiu em disparada com o bico acionado no tanque”.

Quanto às trabalhadoras, foram encontrados os seguintes resultados: do total de 24 mulheres frentistas, dez são nuligestas (nunca engravidaram) e 14 tiveram de uma a três gestações. Dessas últimas, duas relataram que tiveram partos prematuros, três tiveram partos com fórceps, três sofreram aborto espontâneo. Seis mulheres estavam sem informação registrada.

Em relação à presença de outros fatores de riscos que podem potencializar os efeitos da exposição, foram identificados que 14\% dos trabalhadores eram tabagistas, 48,5\% consumiam bebidas alcoólicas "socialmente" e 5,1\% relataram ter feito uso de drogas ilícitas (maconha, cocaína etc.).

\section{Caracterização da exposição dos trabalhadores a riscos ambientais}

A maioria dos trabalhadores referiu consumir água potável da rede pública $(54,4 \%)$ e água engarrafada (38,2\%). Na ocasião da Inspeção da Vigilância pelo projeto foi constatado num dos PRC a utilização da água de poço artesiano por oito trabalhadores.

Quanto à procedência da água do lava-rápido, trinta e nove trabalhadores relataram que era de poços artesianos, doze informaram ser proveniente da rede pública e um de caminhão-pipa. Mais da metade $(n=69,50,8 \%)$ dos trabalhadores não souberam informar a procedência da água.

Em relação ao relato dos trabalhadores de possível exposição ao solo contaminado por combustíveis, $41,9 \%$ fizeram referência ao fato de estarem presentes durante a reforma do posto na substituição de tanques subterrâneos.

Houve relato de mal-estar por exposição a vapores de combustíveis em 32,4\% dos trabalhadores atendidos. A situação de exposição mais citada foi a realização de coleta de amostra do caminhão-tanque durante o descarregamento do combustível.

Foi relatado, também, por uma parte dos trabalhadores $(22,8 \%)$ o uso do combustível etanol como produto de limpeza na residência (acender churrasqueira) ou no trabalho (limpeza da bomba, vidros de carro, piso da loja de conveniência).

Do total de trabalhadores, 94,2 e 92,0\%, respectivamente, informaram que os descartes das embalagens de óleo lubrificante e do óleo queimado foram realizados por empresas de coleta especial, diferentemente do destino dado ao "paninho", que de acordo com $83 \%$ dos relatos era descartado no lixo comum.

Orientações e recomendações fornecidas aos trabalhadores

Antes de preencher a ficha de acolhimento, o trabalhador era informado sobre o motivo de sua convocação e sobre o projeto. Em cada item da ficha que o trabalhador era interrogado, os acolhedores orientavam quanto aos procedimentos e hábitos de risco, como:

- Deixar de utilizar o "paninho" pelo risco de absorção do combustível por meio da pele e via respiratória;

- Distanciar o rosto do trabalhador no momento do abastecimento até "a boca do tanque", argumentando que o uso de abastecimento 
automático é o indicado, por diminuir a exposição aos vapores dos combustíveis;

- Utilizar sempre o abastecimento automático, e quando houver qualquer irregularidade na bomba de abastecimento, informar imediatamente o responsável para tomar as devidas providências, além de solicitar sempre a realização de manutenção preventiva. Em casos de negligência por parte do empregador, denunciar ao Sindicato ou à Visa do município;

- Utilizar o abastecimento automático também contribui com a melhoria das condições ambientais, por evitar vazamentos pelo respiro do carro ou extravasamento de combustíveis pela boca do tanque;

- Utilizar manta ou outro material adequado para absorção do combustível quando ocorre vazamento no solo;

- Tomar banho e trocar de roupa/uniforme quando ocorrer acidentalmente o "banho de combustível” e comunicar a seu responsável para que tome as devidas providências: abertura da Comunicação de Acidente de Trabalho (CAT), ficar atento a qualquer sintoma ou manifestação que se apresente e reparar o problema que ocasionou o acidente;

- Perguntar para o cliente qual o tipo de combustível a ser abastecido, eliminado assim o hábito de "cheirar a tampa" do tanque;

- Utilizar equipamento/mangueira apropriada para retirada de combustível, para não aspirá-lo com a boca;

- Lavar a roupa/uniforme de trabalho separadamente das outras roupas da família, utilizando luvas de borracha e sem reaproveitamento dessa água;

- Usar os EPI (luva, óculos e máscara) para realizar a coleta de amostra de combustíveis em caminhão-tanque, ou na medição manual (réguas) do nível de combustíveis nos tanques subterrâneos e, também, na limpeza da caixa separadora de água e óleo, além do uso no procedimento de troca de óleo;

- Orientar os trabalhadores a respeito de seu direito à saúde e de como buscar informações do médico do trabalho sobre o resultado de seus exames laboratoriais, audiológicos, assim como da importância de ter uma cópia desses exames;

- Em relação às intercorrências e acidentes sofridos, os acolhedores realizaram diversas orientações específicas para intoxicações agudas, assaltos, atropelamentos, vazamentos de combustíveis e abertura de CAT.

Todas essas orientações/recomendações foram utilizadas como protocolo de procedimentos resultante do projeto e apoio técnico aos programas de saúde do trabalhador do município, referente à exposição ao benzeno em PRC. Assim, considerando todo resultado e experiência, o projeto foi concluído em 2012 com a elaboração de um folder e de um vídeo: Frentista, olha o benzeno na pista! ${ }^{13}$.

Atualmente, os atendimentos aos trabalhadores de PRC devem ser realizados nas unidades de saúde da rede básica com base no protocolo estabelecido. O fluxo de encaminhamento ao Cerest segue o que já foi estabelecido, ou seja, quando há casos de maior complexidade e com necessidade de maiores investigações. O Cerest, no seu papel de organizar as ações assistenciais em saúde do trabalhador no âmbito da Atenção Básica, passou a incluir esse protocolo em suas ações de educação permanente.

\section{Discussão}

Diante dos resultados, foi identificado que os frentistas realizam cotidianamente procedimentos de trabalho que potencializam riscos podendo levar a uma intoxicação aguda ou crônica pelo contato com a pele, ingestão e inalação de combustíveis ${ }^{13}$. Todavia, deve-se compreender que tais procedimentos são amplamente realizados nessa atividade de trabalho para alcançar as metas de produção demandadas no tempo previsto e na ausência ou insuficiência de:

- Treinamentos permanentes sobre os riscos da exposição ao benzeno, incluindo informações sobre os riscos à saúde das trabalhadoras, levando-se em consideração a existência de estudos $^{14-16}$ que indicam alteração do ciclo e outros problemas menstruais e de fertilidade, bem como aumento no número de abortos espontâneos pela exposição ao benzeno;

- Afastamento do trabalhador dos locais de possível contaminação, por exemplo, quando o posto de combustível está em reforma e seu solo está contaminado ou quando há contato do trabalhador com água de poços artesianos contaminados;

- Fornecimento de EPI de acordo com os riscos;

- Manutenção das bombas e bicos automáticos;

- Campanha para conscientização da população (cidadãos/consumidores) a respeito dos 
benefícios do abastecimento dos veículos no automático. Um exemplo é a campanha realizada pelo Governo do Estado de Santa Catarina ${ }^{17}$;

- Campanha de conscientização da população, principalmente jovens, sobre a exposição ao benzeno, pois os PRC passaram a ser considerados como "ponto de encontro" da juventude;

- Política Pública preventiva impedindo que outros tipos de estabelecimentos (lanchonetes, bancos, vídeolocadoras, farmácias, restaurantes etc.) sejam instalados nesses espaços.

Vale ressaltar que o uso do "paninho" e o "encher até a boca do tanque" muitas vezes são procedimentos utilizados pelos frentistas como estratégia para não serem repreendidos pelos consumidores, tanto por causa dos possíveis vazamentos, quanto pela cultura existente de que é melhor completar até o valor monetário dar número inteiro, assim como acreditar que encher até a boca do tanque é o melhor.

Considera-se que há muito a ser discutido sobre possíveis correlações entre informações advindas das consultas médicas e outras questões oriundas dos acolhimentos, como a possibilidade de risco adicional à exposição do benzeno devido aos antecedentes ocupacionais em outras atividades laborais com exposição a outros produtos químicos e/ou ao uso demasiado do tabaco ${ }^{14}$.

Diante disso, pode-se afirmar que o acolhimento do Projeto frentista, como intervenção coletiva, pode ser considerado como procedimento com base no acolhimento com Classificação de Risco e Vulnerabilidade ${ }^{18}$, que prioriza e busca uma adequação da capacidade resolutiva de atendimento. Nesses acolhimentos a "escuta" foi muito valorizada, uma vez que os profissionais do Cerest conheceram, a partir do relato dos trabalhadores, tanto os riscos encontrados nessas atividades laborativas quanto os decorrentes de contaminações ambientais, permitindo também identificar a percepção de risco pelo trabalhador. Como comentado: "Acolher é ouvir de forma qualificada o paciente, entendê-lo e poder dessa forma desenvolver a melhor conduta para a situação, pressupondo também uma redução na centralidade das consultas médicas e melhor utilização do potencial dos demais profissionais da unidade". ${ }^{19}$

A construção da ficha de acolhimento aconteceu de forma interativa durante a integração de saberes entre os próprios trabalhadores e os profissionais do Cerest e da Visa. O processo de comunicação entre os atores foi interativo e acredita-se que a compreensão foi facilitada pelo fato da escolaridade da maioria deles ser de nível médio ${ }^{20}$. Vale ressaltar que a ficha de acolhimento foi reformulada pela equipe de acolhedores ao menos três vezes, com acréscimo e qualificação de dados, exclusão de informações repetitivas ou reescrita de questões. Da mesma forma, o conteúdo e a forma das abordagens realizadas pelas acolhedoras foram modificados, apropriados e absorvidos pela equipe, conforme evoluía a aquisição dos conhecimentos inerentes às atividades laborativas em questão.

Tal aprendizado foi possível por parte da equipe porque os profissionais se dispuseram a trabalhar com a escuta qualificada e a implantar novos instrumentos e outros modos de "fazer", norteados por premissas éticas, políticas e clínicas. Assim, a equipe técnica priorizou uma abordagem com o trabalhador de acordo com o Método da Tríplice Inclusão, uma prática social que é "ampliadora dos vínculos de solidariedade e coresponsabilidade" ${ }^{21}$. Ou seja, o acolhimento teve como base os princípios da integralidade do SUS (Política Nacional de Humanização - PNH), que foi inserida nas discussões práticas da equipe, abrangendo a concepção de saúde/doença, o funcionamento dos serviços de saúde em rede, a organização do processo de trabalho no campo da saúde e sua indissociabilidade, inclusive na assistência como uma das práticas de cuidado ${ }^{21}$, buscando afirmar uma prática que se contrapõe ao reducionismo e à fragmentação da assistência e vigilância em saúde:

\begin{abstract}
A inclusão tem o propósito de produzir novos sujeitos, capazes de ampliar suas redes de comunicação, alterando as fronteiras dos saberes e dos territórios de poder; e de conectar suas práticas de produção de saúde ao campo da gestão [...]. É necessário que esta inclusão, assim como o processo de produção de subjetividade a ela associado sejam orientados por princípios e diretrizes. Para a PNH estas orientações são clínicas, políticas e éticas e tomam sentido no acolhimento, na clínica ampliada, na democracia das relações, na valorização do trabalhador, na garantia dos direitos dos usuários e no fomento de redes. ${ }^{21}$
\end{abstract}

Acredita-se que a inclusão foi realizada porque os trabalhadores tanto compartilharam as tarefas reais e o trabalho real com os profissionais da Assistência e da Vigilância em Saúde como informaram os demais colegas da categoria profissional sobre os riscos. E, também, porque esses trabalhadores se responsabilizaram pela saúde própria e dos demais familiares, já que aderiram aos tratamentos, realizaram os exames e compareceram às consultas. Assim, reforça-se o emprego da integralidade, uma vez que, segundo Gomes e Pinheiro ${ }^{22}$ :

Em que pese à concordância de que a integralidade continua sendo um conceito em construção, realizamos um exercício teórico de formulação de uma definição operatória de integralidade como modo 
de atuar democrático, do saber fazer integrado, em um cuidar que é mais alicerçado numa relação de compromisso ético-político, de sinceridade, responsabilidade e confiança. Entende-se o sujeito como ser real, que produz sua história e é responsável pelo seu devir. Respeita-se os saberes das pessoas (saber particular e diferenciado), saberes históricos que foram silenciados e desqualificados, e que, neste estudo, representam uma atitude de respeito que possa expressar compromisso ético nas relações gestores/profissionais/usuários. [...] Isto posto, podemos reconhecer, nas estratégias de melhoria de acesso e desenvolvimento de práticas integrais, o acolhimento, o vínculo e a responsabilização como práticas integrais. O acolhimento, enquanto diretriz operacional, propõe inverter a lógica da organização e do funcionamento do serviço de saúde, e que este seja organizado de forma usuário-centrado. [...] Os mesmos autores defendem o acolhimento como dispositivo para interrogar processos intercessores que constroem relações nas práticas de saúde, buscando a produção da responsabilização clínica e sanitária e a intervenção resolutiva, reconhecendo que, sem acolher e vincular, não há produção dessa responsabilização. ${ }^{22}$

Além disso, após a organização desse acolhimento e sua abordagem diferenciada, por integrar especificidades do trabalho em PRC e a história dos trabalhadores, vislumbra-se a possibilidade de utilizar essa experiência para subsidiar a constituição de protocolos específicos por ramo de atividade, como estratégia de vigilância em saúde que se orienta pelo reconhecimento da centralidade do trabalho e seu impacto à saúde dos trabalhadores. Considera-se que o protocolo possa contribuir com a ampliação do acesso a informações mais detalhadas e específicas, para permitir melhor compreensão dos riscos que se fazem presentes nessa atividade de trabalho, de forma a orientar a abordagem das equipes da atenção básica, assim como o acolhimento permite ao trabalhador momentos de troca de informações a respeito dos riscos a que está exposto.
A elaboração do Protocolo de atendimento para os trabalhadores de PRC, mediante planejamento de ações de Vigilância em Saúde, pode compor a agenda de ações dirigidas a grupos de riscos. Essa estratégia, aliada ao processo de capacitação dos profissionais da rede básica, pode propiciar elementos importantes para subsidiar atenção aos riscos e vulnerabilidade dessa categoria profissional. Diante disso, reafirma-se a concepção da Política Nacional de Humanização ${ }^{10}$, apresentando a potencialidade do acolhimento, como um dos instrumentos capaz de:

\begin{abstract}
Ampliar a qualificação técnica dos profissionais e das equipes em atributos e habilidades relacionais de escuta qualificada, de modo a estabelecer interação humanizada, cidadã e solidária com usuários, familiares e comunidade, bem como o reconhecimento e atuação em problemas de saúde de natureza aguda ou relevantes para a saúde pública. A elaboração de protocolos, sob a ótica da intervenção multi e interprofissional na qualificação da assistência, legitima a inserção do conjunto de profissionais ligados à assistência na identificação de risco e na definição de prioridades, contribuindo, assim, para a formação e o fortalecimento da equipe ${ }^{10}$.
\end{abstract}

Por fim, a experiência do acolhimento demonstrou ser uma modalidade de operacionalização do trabalho em saúde que pode ser aplicada a grupos ocupacionais para identificação dos determinantes sociais, políticos e econômicos a que estão submetidos os trabalhadores e dos mecanismos em que se estabelecem as relações entre trabalho, saúde e ambiente no sistema capitalista ${ }^{4}$. Entretanto, para a garantia e efetiva manutenção das medidas de proteção nos ambientes de trabalho, são necessários o conhecimento sobre os riscos ocupacionais e seus efeitos, a organização dos trabalhadores e a defesa da saúde no trabalho.

\section{Contribuições de autoria}

Todas as autoras participaram igualmente no delineamento do projeto, no levantamento, na análise e interpretação dos dados, na elaboração do manuscrito e tiveram contribuição importante na revisão crítica e na aprovação final da versão publicada.

\section{Agradecimentos}

Aos trabalhadores dos PRC que compartilharam seus saberes conosco e aos representantes dessa categoria profissional (Sindicato dos Frentistas). Aos empregadores e ao Sindicato Patronal por terem compreendido a relevância e a necessidade deste trabalho. A todos os profissionais envolvidos nas Comissões Estadual e Regional do Benzeno, na Assistência e na Vigilância em Saúde (Cerest e Visa da Secretaria Municipal de Campinas). Aos colegas da Fundacentro/Campinas e do Centro Técnico Nacional/SP, do Cesat/BA, da Superintendência Regional do Trabalho e Emprego de São Paulo/MTb, da Gerência Regional do Trabalho e Emprego em Campinas/MTb, da Secretaria Municipal de Saúde de Porto Alegre/RS e do Cesteh/ENSP/Fiocruz; cumprimentando a todos pelo envolvimento e empenho na construção deste trabalho multidisciplinar, intersetorial e interinstitucional. 


\section{Referências}

1. Sallum S. Delegacia Regional do Trabalho abre investigação para avaliar a saúde dos empregados dos postos de combustíveis do Distrito Federal. Dois frentistas podem ter sido intoxicados por benzeno. Correio Braziliense, Brasília, DF, 11 jan. 2006.

2. Campinas. Secretaria Municipal de Saúde. Estudos de avaliação de risco por resíduos perigosos no bairro Mansões Santo Antônio. Município de Campinas: São Paulo [Internet]. Campinas; Secretaria Municipal de Saúde; 2005 [acesso em 2015 nov 18]. Disponível em: http://2009. campinas.sp.gov.br/saude/visa/mansoes_sto_ antonio/conclusoes_recomend.pdf

3. Paulínia. Protocolo de atenção e Vigilância à Saúde de populações expostas aos contaminantes ambientais gerados pelas empresas Shell, Cyanamid e Basf em Paulínia, SP [Internet]. Paulínia; 2007 [acesso em 2015 nov 18]. Disponível em: http://www.acpo.org.br/saudeambiental/ CGVAM/02_Avaliacao_de_Risco/06_shell_basf_ paulinia_sp/protocolo_atendimento_2007.pdf

4. Santos APL, Lacaz FAC. Ações de vigilância em saúde do trabalhador e ambiente: análise da atuação do Centro de Referência em Saúde do Trabalhador de Campinas em postos de combustível. Rev Bras Saúde Ocup. 2013;38(128):230-42.

5. Bahia. Centro Estadual de Saúde do Trabalhador. Divisão de Vigilância em Saúde do Trabalhador. Secretaria Estadual de Saúde. Projeto de Vigilância da Saúde dos trabalhadores de postos de revenda de combustíveis a varejo no estado da Bahia [CDROM]. Salvador; Cest, 2008.

6. Machado JMH, Costa DF, Cardoso LM, Arcuri A. Alternativas e processos de vigilância em saúde do trabalhador relacionados à exposição ao benzeno no Brasil. Ciênc Saúde Coletiva. 2003;8(4):913-21.

7. Paim JS. Vigilância da saúde: dos modelos assistenciais para a promoção da saúde. In: Czeresnia D, Freitas CM, organizadores. Promoção da saúde: conceitos, reflexões e tendências. Rio de Janeiro: Fiocruz; 2003. p. 161-74.

8. Brasil. Ministério da Saúde. Programa Nacional de Vigilância da Qualidade da Água para Consumo Humano [Internet]. [acesso em 2015 nov 18]. Disponível em: http://portalsaude.saude.gov.br/ index.php?option $=$ com_content\&view $=$ article\&id $=11084 \&$ Itemid $=683$

9. Brasil. Ministério da Saúde. Vigilância em Saúde de Populações Expostas a Solo Contaminado [Internet]. Brasília, DF; Ministério da Saúde; 2005 [acesso em 2015 nov 18]. Disponível em: http://portalsaude.saude.gov.br/index. php/o-ministerio/principal/leia-mais-oministerio/1116-secretaria-svs/vigilancia-de-a-a-z/ contaminantes-quimicos/16159-vigipeq-vigisolocontaminantes-quimicos
10. Brasil. Ministério da Saúde. Secretária de Atenção à Saúde. Núcleo Técnico da Política Nacional de Humanização. Acolhimento nas práticas de produção de saúde. Série B. Textos Básicos de Saúde. 2. ed. Brasília, DF: Editora do Ministério da Saúde; 2010. p. 6, p. 30.

11. Cecilio LCO, organizadores. Inventando a mudança na saúde. São Paulo: Hucitec; 1994. 334 p.

12. Merhy EE. Em busca do tempo perdido: a micropolítica do trabalho vivo em saúde. In: Merhy EE, Onocko R, organizadores. Agir em saúde: um desafio para o público. São Paulo: Hucitec; 1997. p. 11.

13. Campinas. Núcleo de Comunicação da Secretaria Municipal de Saúde. Centro de Referência em Saúde do Trabalhador. Fundacentro. Frentista, olha o Benzeno na Pista! Olívio Britto Jr. [vídeo] [Internet]. 2012 [acesso em 2015 nov 18]. Disponível em: https://www.youtube.com/ watch?v=25i35dS8sJI

14. Abel AS, Costa DF, Possebon J, et al. Efeitos da exposição ao benzeno para a saúde. São Paulo: Fundacentro; 2012. 52 p. (série benzeno, fascículo 1).

15. Xu X, Cho SI, Sammel M, You L, Cui S, Huang Y, et al. Association of petrochemical exposure with spontaneous abortion. Occup Environ Med.1998;55(1):31-6.

16. Thurston SW, Ryan L, Christiani DC, Snow R, Carlson J, You L, et al. Petrochemical exposure and menstrual disturbances. Am J Ind Med.2000;38(5):555-64.

17. Brasil. Sistema Único de Saúde. Complete o tanque só até o automático é uma medida a favor da saúde e contra o desperdício. Brasília, DF: SUS; 2010.

18. Paulon SM, Elahel ALS. A construção de um observatório de práticas da Política Nacional de Humanização do Sistema Único de Saúde: a experiência do Rio Grande do Sul. Boletim da Saúde.2006 jul/dez;20(2):121-34.

19. Cardillo MH. Análise comparativa do perfil do paciente do Cerest/Campinas antes e depois da descentralização do atendimento para as unidades básicas de saúde [monografia]. São Paulo: Universidade de São Paulo; 2007. p. 7.

20. Zangirolani LTO, Cordeiro R, Medeiros MAT, Stephan C. Topologia do risco de acidentes do trabalho em Piracicaba, SP. Rev Saúde Pública. 2008;42(2):287-93.

21. Brasil. Ministério da Saúde. Secretaria de Atenção à Saúde. Política Nacional de Humanização. Formação e intervenção. Brasília, DF: Ministério da Saúde; 2010. p. 7-8. (Série B. Textos Básicos de Saúde, Cadernos HumanizaSUS).

22. Gomes MCPA, Pinheiro, R. Acolhimento e vínculo: práticas de integralidade na gestão do cuidado em saúde em grandes centros urbanos. Interface. 2005;9(17):287-301. 